\title{
Risk Analysis for Critical Infrastructures Using Fuzzy TOPSIS
}

\author{
Morteza Yazdani (Corresponding Author) \\ MSc of Economy, Faculty of Economy, Isfahan University, Isfahan, Iran \\ E-mail: abdalrezaych@gmail.com
}

\begin{abstract}
Ali Alidoosti
MSc of Mechanic Engineering, Malek-e-Ashtar University of Technology, Tehran, Iran E-mail: a_alidoost@yahoo.com

Mohammad Hossein Basiri

Assistant Professor of Tarbiat Modares University, Engineering Faculity, Tehran, Iran

E-mail: mhbasiri@modares.ac.ir
\end{abstract}

Received: September 20, 2011 Accepted: October 19, 2011 Published: January 1, 2012

doi:10.5296/jmr.v4i1.979 URL: http://dx.doi.org/10.5296/jmr.v4i1.979

\begin{abstract}
Critical infrastructures are the most important sector in countries because of the essentiality of nation security, public safety, socioeconomic security, and way of life. According to the importance of infrastructures, it is a necessity to analyze the potential risks to do not allow these risks convert into events. The main purpose of this paper is to provide a developed framework with the aim to overcome limitations of the classical approach to build a more secure, safer, and more resilient critical infrastructures in order to develop, implement, control. The proposed framework extends conventional RAMCAP (Risk Analysis and Management for Critical Asset Protection) through introducing new parameters the effects on risk value. According to the complexity of problem and the inherent uncertainty, this research adopts the fuzzy TOPSIS as a fuzzy multi criteria decision making technique to determine the weights of each criterion and the importance of alternatives with respect to criteria. Case analysis is implemented to illustrate the capability and effectiveness of the model for ranking the risk of critical infrastructures. The proposed model demonstrates a significant
\end{abstract}


improvement in comparison with conventional RAMCAP.

Keywords: Critical Infrastructures, Fuzzy TOPSIS, RAMCAP, Risk Ranking 


\section{Introduction}

The countries of all around the world were recently faced with several events generated by various causes in the critical infrastructures sector. They have led to a lot of casualties and major damage to human, machinery, and environment. That is demonstrated by many events which risk connected with security, safety, health, and environment cannot be perfectly avoided. Therefore, miscellaneous methodologies were developed in order to analyze and rank the existing risks. Risk Analysis and Management for Critical Asset Protection (RAMCAP) methodology is one the most well-known methods in this field that were presented by the Department of Homeland Security. The RAMCAP method is a function of three components threat (T), vulnerability (V), and consequence (C) (Brashear et al., 2007; ASME-ITI, 2006; Cox, 2009).

Regardless of the relative importance weights of the evaluation criteria, it appears to be an urgent need for critical infrastructures to develop a risk assessment methodology to manage the effective components.

TOPSIS is one of the most application multi criteria decision making (MADM) methods, which assigns the best alternative among a pool of feasible alternatives by calculating the distances from the positive and negative ideal solutions. This technique is criticized due to neglect uncertainty. On the other hand, fuzzy logic is able to model the uncertainty. This technique uses linguistic variable instead of traditional quantitative expression, which is a very helpful concept for dealing with situations which are too complex or not well-defined enough (Zadeh, 1965). Therefore, fuzzy TOPSIS is developed in order to solve different aspects of priority issues.

Jolai et al. (2011) proposed a two-phase approach for supplier selection and order allocation problem under fuzzy environment. The proposed model in this paper contain of two phases, in the first phase of the approach, a fuzzy multiple criteria decision making method is used to obtain the overall ratings of alternative suppliers, and to select the most qualified ones for further evaluations, in the second phase, a multi-objective mixed integer linear programming (MOMILP) model to determine the order quantities of each selected supplier for each product in each period is constructed. Kaya \& Kahraman (2011) proposed a modified fuzzy TOPSIS methodology for the selection of the best energy technology alternative.

Kelemenis et al (2011) extend fuzzy TOPSIS for support managers' selection. Grassi et al (2009) proposed an integrated estimative approach based on the fuzzy logic theory, which permits more coherence in the evaluation process, producing a very suitable final rank of hazardous activities.

Yu \& Hu (2010) developed an integrated multi criteria decision making approach that combines the voting method and the fuzzy TOPSIS method to evaluate the performance of multiple manufacturing plants in a fuzzy environment. Sadi-Nezhad \& Damghani (2010) presented a TOPSIS approach based on preference ratio and an efficient fuzzy distance measurement in assessment of traffic police centers performance.

Torlak et al (2011) used fuzzy TOPSIS multi-methodological approach in the Turkish 
domestic airline industry. Singh \& Benyoucef (2011) proposed a fuzzy TOPSIS based methodology along with a mechanism for determination of fuzzy linguistic value of each attribute. They utilized entropy method to enumerate the weights of various attributes automatically without involvement of decision makers. Liao \& Kao (2011) proposed integrated fuzzy TOPSIS and multi-choice goal programming (MCGP) approach to solve the supplier selection problem. They stated the advantage of this method is that it allows decision makers to set multiple aspiration levels for supplier selection problems.

Based on fuzzy TOPSIS Krohling \& Campanharo (2011) proposed a fuzzy TOPSIS for group decision making, which is applied to evaluate the ratings of response alternatives to a simulated oil spill. Sun \& Lin (2009) used fuzzy TOPSIS as the analytical tool that determines the weights of each criterion, from their research results, the security and trust are the most important factors for improving the competitive advantage of shopping website. It is clear that fuzzy TOPSIS has demonstrated its capabilities and efficiencies as a practical engineering and problem-solving tool.

In this paper, we extend the approach of TOPSIS to develop a risk-based methodology under fuzzy environment. Fuzzy TOPSIS is adopted because of its capability and efficiency in handling uncertainty, simultaneous consideration of the positive ideal and the negative solutions, simple computations, and logical concepts.

The rest of the paper is organized as follows: In Sections 2, the basic structure of the RAMCAP methodology is introduced. Section 3 describes fuzzy TOPSIS technique. The proposed framework is summarized in Section 4, including risks identification, selection of criteria, risk evaluation using fuzzy TOPSIS procedure, and sensitivity analysis. In Section 5, study for risk evaluation in an illustrative case is presented. The comparison of the proposed model with the conventional RAMCAP is implemented and results are discussed in Section 6. Conclusions are discussed and some shortages of the conventional RAMCAP are listed in Section 7.

\section{The Basic Concepts of RAMCAP Methodology}

The RAMCAP methodology provides a systematic process to identify and analyze the significance of potential events associated with critical infrastructures. The RAMCAP process is comprised of seven steps as follows (ASME-ITI, 2006; Brashear et al., 2007):

(1)Asset characterization and screening, (2) Threat characterization, (3) Consequence analysis, (4) Vulnerability analysis, (5) Asset attractiveness and threat assessment, (6) Risk assessment, and (7) Risk management. This steps are depicted in Figure 1.

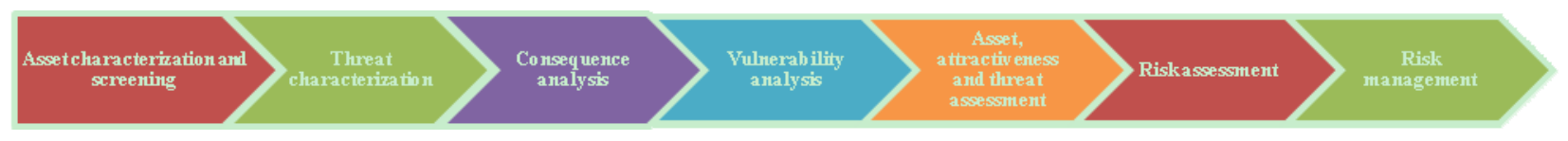

Figure 1. Process of RAMCAP technique 
The benefits of conventional RAMCAP, but are not limited to, include (Brashear \& Jones, 2010): (i) More efficient management of capital and human resources, (ii) Ability to identify the assets with the greatest need and value of improvement, (iii) rational allocation of resources to maximize the security and resilience enhancement within a finite budget.

According to the conventional RAMCAP technique, risk (R) is determined by the intersection of consequences of the attack $(\mathrm{C})$, the threats of the attack $(\mathrm{T})$ and vulnerabilities to the attack (V). More specifically, risk is formulated as Eq. (1):

$$
\mathrm{R}=\mathrm{C} \times \mathrm{T} \times \mathrm{V}
$$

\section{Fuzzy TOPSIS}

\subsection{Fuzzy Theory}

Adequate knowledge and comprehensive data base on a number of different problems are requested to analyze critical infrastructures. There are a close relationship between complexity and certainty, so that; increasing the complexity lead to decrease the certainty. Fuzzy logic -introduced by Zadeh (1965) - can take into account uncertainty and solve problems where there are no sharp boundaries and precise values. Fuzzy logic provides a methodology for computing directly with words (Zadeh, 1996).

Fuzzy set is a powerful mathematical tool for handling the existing uncertain in decision making. A fuzzy set is general form of a crisp set. A fuzzy number belong to the closed interval 0 and 1, which 1 addresses full membership and 0 expresses non-membership. Whereas, crisp sets only allow 0 or 1 . There are different types of fuzzy numbers that can be utilized based on the situation. It is often convenient to work with triangular fuzzy numbers (TFNs) because they are computed simply, and are useful in promoting representation and information processing in a fuzzy environment (Torlak et al, 2011).

A fuzzy number $\tilde{A}$ on R can be a triangular fuzzy number (TFN) if its membership function $\mu_{\tilde{A}}(x): R \rightarrow[0,1]$ be defined as follows:

$$
\mu_{\tilde{A}}(x)= \begin{cases}0, & x \leq a \\ (x-a) /(b-a), & a \leq x \leq b \\ (c-x) /(c-b), & b \leq x \leq c \\ 0, & \text { otherwise }\end{cases}
$$

\subsection{Fuzzy TOPSIS Approach}

TOPSIS is based on the concept that the chosen alternative should have the shortest distance from the positive-ideal solution and the longest distance from the negative-ideal solution (Seçme et al, 2009; Gumus, 2009; Sun, 2010; Yue, 2011). The positive ideal solution is a solution that maximizes the benefit criteria and minimizes the cost criteria simultaneously, whereas the negative ideal solution maximizes the cost criteria and minimizes the benefit 
criteria simultaneously.

In the conventional TOPSIS technique, expert judgments are represented with precise values. In real world problems, it is often difficult for a decision maker to determine precise weights for criteria and alternatives with respect to the criteria under consideration. The merit of using a fuzzy approach is to determine the importance or preference of criteria and alternatives using fuzzy numbers instead of crisp numbers to be more adapted to the real world cases. For this reason, fuzzy TOPSIS was developed to solve the real world problems under fuzzy environment (Kuo et al, 2007; Yang, Hung, 2007; Chen, Tsao, 2008; Ashtiani et al, 2009; Ebrahimnejad et al, 2009; Roghanian et al, 2010; Aydogan, 2011; Jolai et al, 2011; Awasthi et al, 2011) . This technique helps decision-makers carry out analysis and comparisons in ranking their preference of the alternatives with vague or imprecise data (Yu \& Hu, 2010).

The mathematics concept of Fuzzy TOPSIS can be described as follows:

Step 1: Choose the linguistic ratings for criteria and alternatives with respect to criteria.

In this step, the importance weights of evaluation criteria and the ratings of alternatives are considered as linguistic terms to assess risk under fuzzy environment as shown in Table 1 and Table 2.

Table 1. Linguistic terms for criteria

\begin{tabular}{|l|c|}
\hline Linguistic terms & Fuzzy number \\
\hline Very low (VL) & $(0.0,0.0,0.25)$ \\
\hline Low (L) & $(0.0,0.25,0.5)$ \\
\hline Medium (M) & $(0.25,0.5,0.75)$ \\
\hline High (H) & $(0.5,0.75,1.0)$ \\
\hline Very High (VH) & $(0.75,1.0,1.0)$ \\
\hline
\end{tabular}

Table 2. Linguistic rating for alternatives

\begin{tabular}{|l|c|}
\hline Linguistic terms & Fuzzy rating \\
\hline Very Poor (VP) & $(0.0,0.0,2.5)$ \\
\hline Poor (P) & $(0.0,2.5,5.0)$ \\
\hline Fair (F) & $(2.5,5.0,7.5)$ \\
\hline Good (G) & $(5.0,7.5,10.0)$ \\
\hline Very Good (VG) & $(7.5,10.0,10.0)$ \\
\hline
\end{tabular}

Step 2. Construct the fuzzy decision matrix.

If assume that the number of criteria is $n$ and the count of alternatives is $m$, fuzzy decision matrix will be obtained with $m$ rows and $n$ columns as following matrix: 


$$
\tilde{D}=\left[\begin{array}{cccc}
C_{1} & C_{2} & \cdots & C_{n} \\
\tilde{x}_{11} & \tilde{x}_{12} & \cdots & \tilde{x}_{1 n} \\
\tilde{x}_{21} & \tilde{x}_{22} & \cdots & \tilde{x}_{2 n} \\
\vdots & \vdots & \ddots & \vdots \\
\tilde{x}_{m 1} & \tilde{x}_{m 2} & & \tilde{x}_{m n}
\end{array}\right] \begin{gathered}
A_{1} \\
A_{2} \\
\vdots \\
A_{m}
\end{gathered}
$$

And criteria are constructed as follows:

$$
\tilde{W}=\left(\tilde{w}_{1}, \tilde{w}_{2}, \ldots, \tilde{w}_{n}\right)
$$

Step 3. After constructing fuzzy decision matrix, the normalization of fuzzy decision matrix is accomplished using linear scale transformation. The calculations are done using formulas (5), (6) to convert the different criteria scales into a comparable scale.

$$
\begin{array}{r}
\tilde{r}_{i j}=\left(\frac{a_{i j}}{c_{j}^{+}}, \frac{b_{i j}}{c_{j}^{+}}, \frac{c_{i j}}{c_{j}^{+}}\right) \text {and } c_{j}^{+}=\max _{i} c_{i j} \text {, for maximization objective } \\
\tilde{r}_{i j}=\left(\frac{a_{j}^{-}}{c_{i j}}, \frac{a_{j}^{-}}{b_{i j}}, \frac{a_{j}^{-}}{a_{i j}}\right) \text { and } a_{j}^{-}=\min _{i} a_{i j} \text {, for minimization objective }
\end{array}
$$

The normalized fuzzy decision matrix can be represented by Eq. (7):

$$
\tilde{R}=\left[\tilde{r}_{i j}\right]_{m \times n}, i=1,2, \ldots, m ; j=1,2, \ldots, n .
$$

Where the $\tilde{r}_{i j}$ is the normalized value of $\tilde{x}_{i j}=\left(a_{i j}, b_{i j}, c_{i j}\right)$.

Step 4. Calculate the weighted normalized fuzzy decision matrix.

The weighted normalized value $\tilde{v}_{i j}$ is calculated by multiplying the weights $\left(\tilde{w}_{j}\right)$ of criteria with the normalized fuzzy decision matrix $\tilde{r}_{i j}$. The weighted normalized decision matrix $\tilde{V}$ for each criterion is calculated through the following relations:

$$
\tilde{V}=\left[\tilde{v}_{i j}\right]_{n \times j}, \quad i=1,2, \ldots, n, j=1,2, \ldots, J
$$

Where

$$
\tilde{v}_{i j}=\tilde{r}_{i j}(\cdot) \tilde{w}_{i}
$$

Step 5. Then the fuzzy positive-ideal solution (FPIS $A^{+}$) and fuzzy negative-ideal solution 
(FNIS $A^{-}$) are determined as described in following part.

$$
\begin{gathered}
A^{+}=\left(\tilde{v}_{1}^{+}, \tilde{v}_{2}^{+}, \tilde{v}_{3}^{+}, \ldots, \tilde{v}_{n}^{+}\right)=\left\{\max _{i} v_{i j} \mid(i=1,2, \ldots, n)\right\} \\
A^{-}=\left(\tilde{v}_{1}^{-}, \tilde{v}_{2}^{-}, \tilde{v}_{3}^{-}, \ldots, \tilde{v}_{n}^{-}\right)=\left\{\min _{i} v_{i j} \mid(i=1,2, \ldots, n)\right\}
\end{gathered}
$$

Based on the weighted normalized fuzzy decision matrix, the ranges belong to the closed interval [0,1]. Therefore, the FPIS and FNIS can be defined as $(1,1,1)$ and $(0,0,0)$ respectively.

Step 6. After assigning the FPIS and FNIS, the distance of each alternative from $A^{+}$and $A^{-}$are calculated by Eqs. (12) and (13):

$$
\begin{gathered}
d_{i}^{+}=\sum_{j=1}^{n} d\left(\tilde{v}_{i j}, \tilde{v}_{j}^{+}\right), i=1,2, \ldots, m \\
d_{i}^{-}=\sum_{j=1}^{n} d\left(\tilde{v}_{i j}, \tilde{v}_{j}^{-}\right), i=1,2, \ldots, m
\end{gathered}
$$

Where the distance measurement between two fuzzy number $\tilde{a}=\left(a_{1}, a_{2}, a_{3}\right)$ and $\tilde{b}=\left(b_{1}, b_{2}, b_{3}\right)$ can be calculated by Vertex method as follows:

$$
d_{v}(\tilde{a}, \tilde{b})=\sqrt{\frac{1}{3}\left[\left(a_{1}-b_{1}\right)^{2}+\left(a_{2}-b_{2}\right)^{2}+\left(a_{3}-b_{3}\right)^{2}\right]}
$$

Step 7. Calculate the closeness coefficient.

The closeness coefficient $\left(C C_{i}\right)$ takes into account the distance of the FPIS, $d_{i}^{+}$and the FNIS,

$d_{i}^{-}$simultaneously. The closeness coefficient of each alternative is obtained through Eq. (15):

$$
C C_{i}=\frac{d_{i}^{-}}{d_{i}^{-}+d_{i}^{+}}
$$

Step 8. Rank preference order.

The ranking of the alternatives can be determined according to the closeness coefficient in descending order.

\section{The Proposed Framework}

The proposed framework for ranking risk in critical infrastructures has following four phases: 


\section{Mll Macrothink}

1. Identify the existing risks.

2. Select the evaluation criteria.

3. Evaluate the identified risks using fuzzy TOPSIS procedure.

4. Sensitivity analysis

\subsection{Risks identification}

In the risk identification phase, threats and hazards which could disrupt the critical services and products should be identified. One of the simplest method of identifying and analyzing the risks in a infrastructure is by asking questions such as which assets are most critical, which assets are more exposed to danger, and getting the right answers.

\subsection{Selection of criteria}

Selection of criteria is the first step for evaluating risk of critical infrastructures. The parameters of the RAMCAP methodology were identified as a part of evaluation criteria. Since these criteria are not enough to cover all aspects of risks; new criteria for a more precise, accurate, and sure risk analysis are developed. These criteria are presented in Table 3.

As shown in Table 3, the first three criteria (i.e. C1, C2, and C3) are the cost type criteria (the lower, the better). The remaining criteria are the benefit type criteria (the higher, the better).

Table 3. Evaluation criteria for analyze risk

\begin{tabular}{|c|c|c|}
\hline Criteria & Definition & $\begin{array}{l}\text { Type of } \\
\text { criterion }\end{array}$ \\
\hline Threat (C1) & Threat is defined as an event with an undesired impact & Cost \\
\hline $\begin{array}{l}\text { Vulnerability } \\
\qquad \text { (C2) }\end{array}$ & $\begin{array}{l}\text { Any weakness of an asset that can convert it into an event } \\
\text { or disaster by one or more threats }\end{array}$ & Cost \\
\hline $\begin{array}{l}\text { Consequence } \\
\text { (C3) }\end{array}$ & Consequence is defined as the effect of an event or incident & Cost \\
\hline $\begin{array}{l}\text { Detectability } \\
\text { (C4) }\end{array}$ & $\begin{array}{l}\text { The capability and potential for identification and } \\
\text { elimination of the weakness }\end{array}$ & Benefit \\
\hline $\begin{array}{l}\text { Reaction } \\
\text { against event } \\
\text { (C5) }\end{array}$ & $\begin{array}{l}\text { The capability of an appropriate response in order to reduce } \\
\text { or limit the effect of an event after happening or prevent } \\
\text { against the development of casualties, damage, and loss }\end{array}$ & Benefit \\
\hline
\end{tabular}

\subsection{Evaluating the existing risks using fuzzy TOPSIS procedure}

In the third phase, evaluating risks is determined by using fuzzy TOPSIS. Linguistic terms are utilized for evaluating the ratings and importance weights of alternatives and criteria. The definition of linguistic terms and triangular fuzzy numbers are presented in Tables (1) and (2).

\subsection{Sensitivity analysis}

Sensitivity analysis is a useful tool in the present of uncertainty in the definition of the relative importance of evaluation criteria. This technique is applied to determine the effect of criteria weights on decision making. 


\section{Case analysis}

The proposed model is utilized to rank the existing risk in a critical infrastructure in order to demonstrate the potential applications of the model. A rail transportation example is adopted from API \& NPRA (2004). The example is of a fictitious hydrocarbon tank truck transportation system, which includes the tank truck, inventory of flammable liquids and the route specific variables such as the type of road, population centers and environmental receptors, and any stops.

\subsection{Risks Identification}

In our case, eight critical assets were identified as risky assets to be analyzed by the model. These assets include 25 railcars of petroleum products (RPP), rural section of track to switch yard - 25 miles from shipper's site (RST), mainline section of track in rural area - 200 miles (MST-200), switch yard (SY), river crossing (RC), mainline section of track in urban area 300 miles (MST-300), siding in Urban Area (SUA), and tunnel in Urban Area (TUA).

\subsection{Selection of Criteria}

From above discussion, evaluation criteria to utilize in the proposed model comprise Threat (C1), Vulnerability (C2), Consequence (C3), Detectability (C4), and Reaction against event (C5). Thus, the decision hierarchy is structured as depicted in Figure 2.

The decision problem consists of three levels: the objective of the problem is situated at the highest level, while in the second level, the criteria are presented, and the last level belongs to the alternatives.

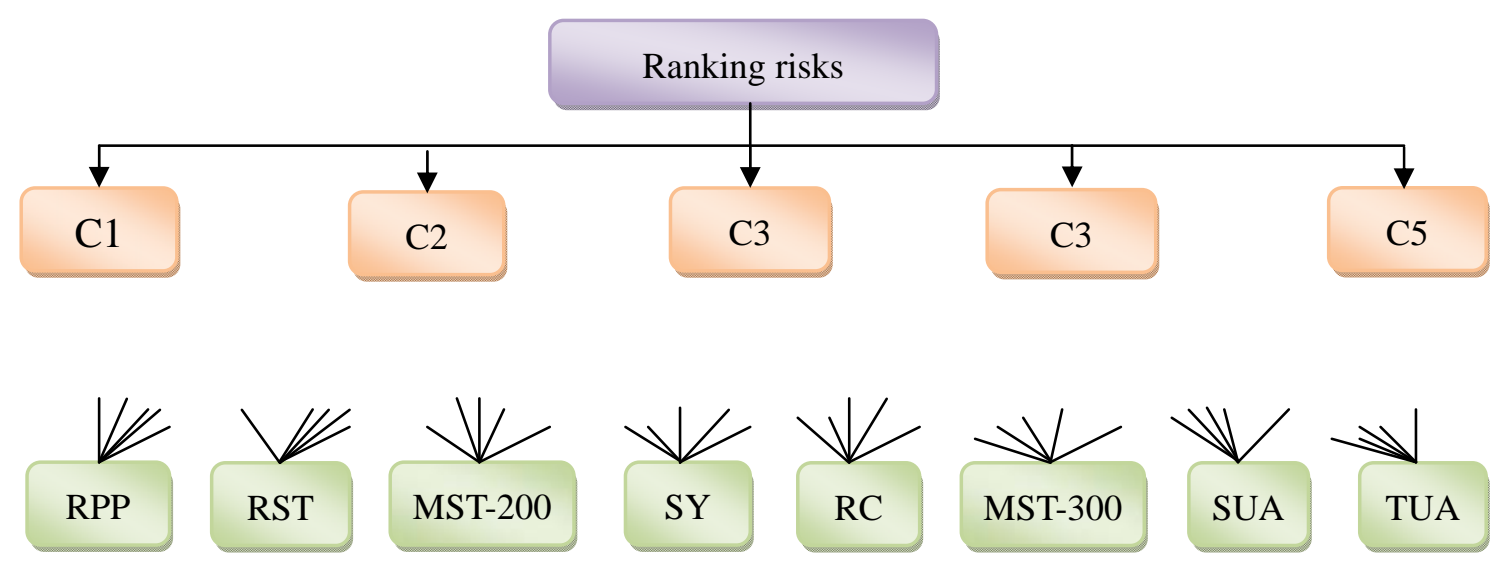

Figure 2. The structure of decision

\subsection{Evaluating the Existing Risks Using Fuzzy TOPSIS Procedure}

Regarding the evaluation of the identified risks, 8 decision makers with minimum 5 years experience were invited to evaluate the weights of criteria and alternatives with respect to each criterion by using linguistic variables given in Table 1 and Table 2. For achieving the aim, two questionnaires are designed; one of them is to obtain the weights of criteria and other is to acquire the importance of alternatives with respect to criteria. To determine the 
fuzzy weight of each criterion, linguistic variables are converted into triangular fuzzy numbers as shown in the third column of Table 4.

Table 4. Fuzzy weights of criteria

\begin{tabular}{lll}
\hline Criteria & Linguistic term & Fuzzy number \\
\hline C1 & M & $(0.25,0.5,0.75)$ \\
C2 & H & $(0.5,0.75,1.0)$ \\
C3 & VH & $(0.75,1.0,1.0)$ \\
C4 & L & $(0.0,0.25,0.5)$ \\
C5 & M & $(0.25,0.5,0.75)$ \\
\hline
\end{tabular}

Then, decision makers were asked to form fuzzy evaluation matrix by linguistic variables presented in Table 2. It is constructed by comparing eight potential risks under five criteria separately. The fuzzy decision matrix is presented in Table 5.

Based on the fuzzy TOPSIS procedure, the decision matrix formed in Table 5 needs to be normalized by using Eqs. (5) and (6). Then, the fuzzy weighted decision matrix for the existing alternatives is calculated by multiplying the weights of criteria with the normalized fuzzy decision matrix as depicted in Table 6.

Table 5. Fuzzy decision matrix

\begin{tabular}{|c|c|c|c|c|c|}
\hline & $\mathrm{C} 1$ & $\mathrm{C} 2$ & $\mathrm{C} 3$ & $\mathrm{C} 4$ & $\mathrm{C} 5$ \\
\hline \multirow[t]{2}{*}{ RPP } & G & $\mathrm{F}$ & G & VG & F \\
\hline & $(5.0,7.5,10.0)$ & $(2.5,5.0,7.5)$ & $(5.0,7.5,10.0)$ & $(7.5,10.0,10.0)$ & $(2.5,5.0,7.5)$ \\
\hline \multirow[t]{2}{*}{ RST } & $\mathrm{F}$ & G & $\mathrm{F}$ & $\mathrm{P}$ & $\mathrm{P}$ \\
\hline & $(2.5,5.0,7.5)$ & $(5.0,7.5,10.0)$ & $(2.5,5.0,7.5)$ & $(0.0,2.5,5.0)$ & $(0.0,2.5,5.0)$ \\
\hline \multirow[t]{2}{*}{ MST-200 } & $\mathrm{F}$ & $\mathrm{F}$ & $\mathrm{P}$ & VG & G \\
\hline & $(2.5,5.0,7.5)$ & $(2.5,5.0,7.5)$ & $(0.0,2.5,5.0)$ & $(7.5,10.0,10.0)$ & $(5.0,7.5,10.0)$ \\
\hline \multirow[t]{2}{*}{ SY } & G & VP & $\mathrm{P}$ & $\mathrm{F}$ & VG \\
\hline & $(5.0,7.5,10.0)$ & $(0.0,0.0,2.5)$ & $(0.0,2.5,5.0)$ & $(2.5,5.0,7.5)$ & $(7.5,10.0,10.0)$ \\
\hline \multirow[t]{2}{*}{$\mathrm{RC}$} & $\mathrm{F}$ & G & $\mathrm{P}$ & $\mathrm{F}$ & VG \\
\hline & $(2.5,5.0,7.5)$ & $(5.0,7.5,10.0)$ & $(0.0,2.5,5.0)$ & $(2.5,5.0,7.5)$ & $(7.5,10.0,10.0)$ \\
\hline \multirow[t]{2}{*}{ MST-300 } & VG & F & $\mathrm{F}$ & $\mathrm{P}$ & G \\
\hline & $(7.5,10.0,10.0)$ & $(2.5,5.0,7.5)$ & $(2.5,5.0,7.5)$ & $(0.0,2.5,5.0)$ & $(5.0,7.5,10.0)$ \\
\hline \multirow[t]{2}{*}{ SUA } & VP & $\mathrm{P}$ & G & VG & G \\
\hline & $(0.0,0.0,2.5)$ & $(0.0,2.5,5.0)$ & $(5.0,7.5,10.0)$ & $(7.5,10.0,10.0)$ & $(5.0,7.5,10.0)$ \\
\hline \multirow[t]{2}{*}{ TUA } & G & G & $\mathrm{F}$ & $\mathrm{P}$ & $\mathrm{F}$ \\
\hline & $(5.0,7.5,10.0)$ & $(5.0,7.5,10.0)$ & $(2.5,5.0,7.5)$ & $(0.0,2.5,5.0)$ & $(2.5,5.0,7.5)$ \\
\hline
\end{tabular}


Table 6. Weighted normalized fuzzy decision matrix

\begin{tabular}{cccccc}
\hline & C1 & C2 & C3 & C4 & C5 \\
\hline RPP & $(0.12,0.37,0.75)$ & $(0.12,0.37,0.75)$ & $(0.37,0.75,1.0)$ & $(0.0,0.0,0.25)$ & $(0.06,0.25,0.56)$ \\
RST & $0.06,0.25,0.56)$ & $(0.25,0.56,1.0)$ & $(0.19,0.5,0.75)$ & $(0.0,0.0,0.12)$ & $(0.0,0.12,0.37)$ \\
MST-200 & $0.06,0.25,0.56)$ & $(0.12,0.37, .075)$ & $(0.0,0.25,0.5)$ & $(0.0,0.0,0.25)$ & $(0.12,0.37, .075)$ \\
SY & $0.12,0.37, .075)$ & $(0.0,0.0,0.25)$ & $(0.0,0.25,0.5)$ & $(0.0,0.0,0.19)$ & $(0.19,0.5,0.75)$ \\
RC & $0.06,0.25,0.56)$ & $(0.25,0.56,1.0)$ & $(0.0,0.25,0.5)$ & $(0.0,0.0,0.19)$ & $(0.19,0.5,0.75)$ \\
MST-300 & $(0.19,0.5,0.75)$ & $(0.12,0.37,0.75)$ & $(0.19,0.5,0.75)$ & $(0.0,0.0,0.12)$ & $(0.12,0.37,0.75)$ \\
SUA & $(0.0,0.0,0.19)$ & $(0.0,0.19,0.5)$ & $(0.37,0.75,1.0)$ & $(0.0,0.0,0.25)$ & $(0.12,0.37, .075)$ \\
TUA & $0.12,0.37, .075)$ & $(0.25,0.56,1.0)$ & $(0.19,0.5,0.75)$ & $(0.0,0.0,0.12)$ & $(0.06,0.25,0.56)$ \\
\hline
\end{tabular}

Then for the eight alternatives, the fuzzy positive ideal solution (FPIS, $A^{+}$) and the fuzzy negative ideal solutions (FNIS, $A^{-}$) are calculated using Eqs. (10), (11). As a result, FPIS and FNIS are defined as $\tilde{v}_{i}^{+}=(1,1,1)$ and $\tilde{v}_{i}^{-}=(0,0,0)$ for benefit criterion, and $\tilde{v}_{i}^{+}=(0,0,0)$ and $\tilde{v}_{i}^{-}=(1,1,1)$ for cost criterion. As mentioned above, C1, C2, and C3 are cost criteria whereas C4 and C5 are benefit criteria.

Then, the distance of each alternative from the fuzzy positive ideal solution and fuzzy negative ideal solution are calculated through Eqs. (12) and (13). For example, the distances of the FPIS and FNIS for alternative A1 are calculated as follows:

$$
\begin{aligned}
& d_{1}^{+}=\sqrt{\frac{1}{3}(0.0-0.13)^{2}+(0.0-0.38)^{2}+(0.0-0.75)^{2}}+\sqrt{\frac{1}{3}(0.0-0.13)^{2}+(0.0-0.38)^{2}+(0.0-0.75)^{2}}+ \\
& \sqrt{\frac{1}{3}(0.0-0.37)^{2}+(0.0-0.75)^{2}+(0.0-1)^{2}}+\sqrt{\frac{1}{3}(1.0-0.0)^{2}+(1-0.0)^{2}+(1.0-0.25)^{2}}+ \\
& \sqrt{\frac{1}{3}(1.0-0.06)^{2}+(1-0.25)^{2}+(1.0-0.56)^{2}}=3.39
\end{aligned}
$$

And

$$
\begin{aligned}
& d_{1}^{-}=\sqrt{\frac{1}{3}(1.0-0.13)^{2}+(1.0-0.38)^{2}+(1.0-0.75)^{2}}+\sqrt{\frac{1}{3}(1.0-0.13)^{2}+(1.0-0.38)^{2}+(1.0-0.75)^{2}}+ \\
& \sqrt{\frac{1}{3}(1.0-0.37)^{2}+(1.0-0.75)^{2}+(1.0-1)^{2}}+\sqrt{\frac{1}{3}(0.0-0.0)^{2}+(0.0-0.0)^{2}+(0.0-0.25)^{2}}+ \\
& \sqrt{\frac{1}{3}(0.0-0.06)^{2}+(0.0-0.25)^{2}+(0.0-0.56)^{2}}=2.16
\end{aligned}
$$

Then,

$$
C C_{1}=\frac{d_{1}^{-}}{d_{1}^{-}+d_{1}^{+}}=0.389
$$




\section{Macrothink}

Similar calculations are fulfilled for the other alternatives and the results are presented in Table 7.

Table 7. Fuzzy TOPSIS result

\begin{tabular}{|c|c|c|c|c|}
\hline & $d_{i}^{+}$ & $d_{i}^{-}$ & $C C_{i}$ & $\begin{array}{c}\text { Rank base } \\
\text { on security }\end{array}$ \\
\hline RPP & 3.394 & 2.164 & 0.389 & 5 \\
\hline RST & 3.374 & 2.108 & 0.384 & 7 \\
\hline MST-200 & 2.731 & 2.786 & 0.505 & 2 \\
\hline SY & 2.467 & 2.978 & 0.546 & 1 \\
\hline RC & 2.868 & 2.656 & 0.480 & 4 \\
\hline MST-300 & 3.150 & 2.337 & 0.425 & 8 \\
\hline SUA & 2.731 & 2.762 & 0.502 & 3 \\
\hline TUA & 3.396 & 2.137 & 0.386 & 6 \\
\hline
\end{tabular}

According to $C C_{i}$ values, the risk ranking in descending order is SY, MST-200, SUA, RC, RPP, TUA, RST and MST-300. Therefore, the riskiest asset is MST-300 and the securest asset is $\mathrm{SY}$.

\subsection{Sensitivity analysis}

Sensitivity analysis plays a significant role in complex decision making because of inherent instability. This technique generates different scenarios that may change the priority of alternatives and be needed to reach a consensus. If the ranking order be changed by increasing or decreasing the importance of the criteria, the results are expressed to be sensitive otherwise it is robust. In this study, sensitivity analysis is implemented to see how sensitive the alternatives change with the importance of the criteria. This tool graphical exposes the importance of criteria weights in selecting the optimal alternative among the feasible alternatives. The main goal of sensitivity analysis is to see which criteria is most significant in influencing the decision making process. For this reason, twenty five experiments were conducted as presented in Table 8. Fig. 3 shows how the priority of each alternative can be changed with increasing or decreasing the importance of the criteria. 
Table 8. Sensitivity analysis

\begin{tabular}{|c|c|c|}
\hline No. & Weights of criteria & Ranking \\
\hline 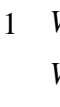 & $\begin{array}{l}W_{C 1, C 5}=(0.25,0.5,0.75), W_{C 2}=(0.5,0.75,1) \\
W_{C 3}=(0.75,1,1), W_{C 4}=(0,0,0.25)\end{array}$ & RST \\
\hline 21 & $W_{C 1, C 2}=(0.5,0.75,1), W_{C 3}=(0.75,1,1), W_{C 4, C 5}=(0$, & $\mathrm{Y}>\mathrm{SUA}>\mathrm{MST}-200>\mathrm{RC}>\mathrm{MST}-300>\mathrm{RST}>\mathrm{RPP}>\mathrm{TUA}$ \\
\hline 31 & $W_{C 1, C 2, C 3}=(0.5,0.75,1), W_{C 4, C 5}=(0,0,0.25)$ & $\mathrm{Y}>\mathrm{SUA}>\mathrm{MST}-200>\mathrm{RC}>\mathrm{MST}-300>\mathrm{RPP}>\mathrm{RST}>\mathrm{TUA}$ \\
\hline $4 \quad 1$ & $W_{C 1, C 2, C 3, C 4}=(0.5,0.75,1), W_{C 5}=(0.25,0.5,0.75)$ & SUA $>$ MST-200 $>$ SY $>$ RC $>$ RPP MST-300 $>$ RST $>$ TUA \\
\hline $5 \quad 1$ & $W_{C 2, C 3, C 4, C 5}=(0.5,0.75,1), W_{C 1}=(0.25,0.5,0.75)$ & $\mathrm{SUA}>\mathrm{SY}>\mathrm{MST}-200>\mathrm{RC}>\mathrm{RPP}$ MST-300 $>$ TUA $>$ RST \\
\hline $6 \quad 1$ & $W_{C 3, C 4, C 5}=(0.5,0.75,1), W_{C 1, C 2}=(0.25,0.5,0.75)$ & UA $>$ MST-200 $>$ SY $>$ RC $>$ RPP MST-300 > TUA $>$ RST \\
\hline $7 \quad 1$ & $W_{C 4, C 5}=(0.5,0.75,1), W_{C 1, C 2, C 3}=(0.25,0.5,0.75)$ & SUA $>$ MST-200 $>$ SY $>$ RC $>$ RPP MST-300 $>$ TUA $>$ RST \\
\hline $8 \quad 1$ & $W_{C 5}=(0.5,0.75,1), W_{C 1, C 2, C 3, C 4}=(0.25,0.5,0.75)$ & $\mathrm{SUA}>\mathrm{SY}>\mathrm{MST}-200>\mathrm{RC}>\mathrm{RPP}$ MST-300 $>$ TUA $>$ RST \\
\hline $9 \quad 1$ & $W_{C 1, C 2, C 3, C 4, C 5}=(0.25,0.5,0.75)$ & JA $>$ MST-200 $>$ SY $>$ RC $>$ RPP MST-300 $>$ TUA $>$ RST \\
\hline $10 V$ & $W_{C 5}=(0,0,0.25), W_{C 1, C 2, C 3, C 4}=(0.25,0.5,0.75)$ & SUA $>$ MST-200 $>$ SY $>$ RC $>$ RPP $>$ RST $>$ MST-300 $>$ TUA \\
\hline $11 V$ & $W_{C 4, C 5}=(0,0,0.25), W_{C 1, C 2, C 3}=(0.25,0.5,0.75)$ & UA $>$ SY $>$ MST-200 $>$ RC $>$ RST $>$ MST-300 $>$ RPP $>$ TUA \\
\hline $12 V$ & $W_{C 1, C 3, C 4, C 5}=(0,0,0.25), W_{C 2}=(0.25,0.5,0.75)$ & $\mathrm{Y}>\mathrm{SUA}>\mathrm{MST}-200>\mathrm{MST}-300>\mathrm{RPP}>\mathrm{RC}>\mathrm{TUA}>\mathrm{RST}$ \\
\hline $13 V$ & $W_{C 1, C 4, C 5}=(0,0,0.25), W_{C 2, C 3}=(0.25,0.5,0.75)$ & $\mathrm{SY}>\mathrm{MST}-200>\mathrm{SUA}>\mathrm{RC}>\mathrm{MST}-300>\mathrm{RPP}>\mathrm{TUA}>\mathrm{RST}$ \\
\hline $14 V$ & $W_{C 1, C 4}=(0,0,0.25), W_{C 2, C 3, C 5}=(0.25,0.5,0.75)$ & Y $>$ MST-200 $>$ SUA $>$ RC $>$ MST-300 $>$ RPP $>$ TUA $>$ RST \\
\hline $15 V$ & $W_{C 1, C 4, C 5}=(0,0,0.25), W_{C 3}=(0.25,0.5,0.75), W_{C 2}=(0.5,0.75,1)$ & SY $>$ MST-200 $>$ SUA $>$ RC $>$ MST-300 $>$ RPP $>$ RST $>$ TUA \\
\hline $16 V$ & $W_{C 1, C 4}=(0,0,0.25), W_{C 3, C 5}=(0.25,0.5,0.75), W_{C 2}=(0.75,1,1)$ & SY $>$ SUA $>$ MST-200 $>$ RC $>$ MST-300 $>$ RPP $>$ RST $>$ TUA \\
\hline $17 V$ & $W_{C 1}=(0,0,0.25), W_{C 3, C 4, C 5}=(0.25,0.5,0.75), W_{C 2}=(0.75,1,1)$ & SY $>$ SUA $>$ MST-200 $>$ RC $>$ MST-300 $>$ RPP $>$ RST $>$ TUA \\
\hline 18 & $\begin{array}{l}W_{C 1}=(0,0,0.25), W_{C 3, C 5}=(0.25,0.5,0.75), W_{C 4}=(0.5,0.75,1) \\
W_{C 2}=(0.75,1,1)\end{array}$ & SY $>$ SUA $>$ MST-200 $>$ RC $>$ MST-300 $>$ RPP $>$ RST $>$ TUA \\
\hline $19 V$ & $W_{C 1}=(0,0,0.25), W_{C 3, C 5}=(0.25,0.5,0.75), W_{C 2, C 4}=(0.75,1,1)$ & $\mathrm{SY}>\mathrm{SUA}>\mathrm{MST}-200>\mathrm{RPP}>\mathrm{RC}>\mathrm{MST}-300>\mathrm{RST}>\mathrm{TUA}$ \\
\hline 20 & $\begin{array}{l}W_{C 1}=(0,0,0.25), W_{C 3}=(0.25,0.5,0.75), W_{C 2, C 4}=(0.75,1,1) \\
W_{C 5}=(0.5,0.75,1)\end{array}$ & SY $>$ SUA $>$ MST-200 $>$ RPP $>$ RC $>$ MST-300 $>$ RST $>$ TUA \\
\hline $21 V$ & $W_{C 1}=(0,0,0.25), W_{C 3}=(0.25,0.5,0.75), W_{C 2, C 4, C 5}=(0.75,1,1)$ & SY $>$ SUA $>$ MST-200 $>$ RC $>$ RPP $>$ MST-300 $>$ RST $>$ TUA \\
\hline 22 & $W_{C 1}=(0,0,0.25), W_{C 3}=(0.5,0.75,1), W_{C 2, C 4, C 5}=(0.75,1,1)$ & SY $>$ MST-200 $>$ SUA $>$ RC $>$ RPP $>$ MST-300 $>$ RST $>$ TUA \\
\hline $23 V$ & $W_{C 1}=(0,0,0.25), W_{C 2, C 3, C 4, C 5}=(0.75,1,1)$ & $\mathrm{SY}>\mathrm{MST}-200>\mathrm{SUA}>\mathrm{RC}>\mathrm{RPP}>\mathrm{MST}-300>\mathrm{RST}>\mathrm{TUA}$ \\
\hline $24 V$ & $W_{C 1}=(0.25,0.5,0.75), W_{C 2, C 3, C 4, C 5}=(0.75,1,1)$ & SY $>$ MST-200 $>$ SUA $>$ RC $>$ RPP $>$ MST-300 $>$ RST $>$ TUA \\
\hline & $W_{C 1}=(0.25,0.5,0.75), W_{C 3}=(0.75,1,1), W_{C 2, C 4, C 5}=(0.5,0.75,1)$ & SY $>$ SUA $>$ MST-200 $>$ RC $>$ RPP $>$ MST-300 $>$ RST $>$ TUA \\
\hline
\end{tabular}




\section{MInstitute Macrothink $^{\text {Int }}$}

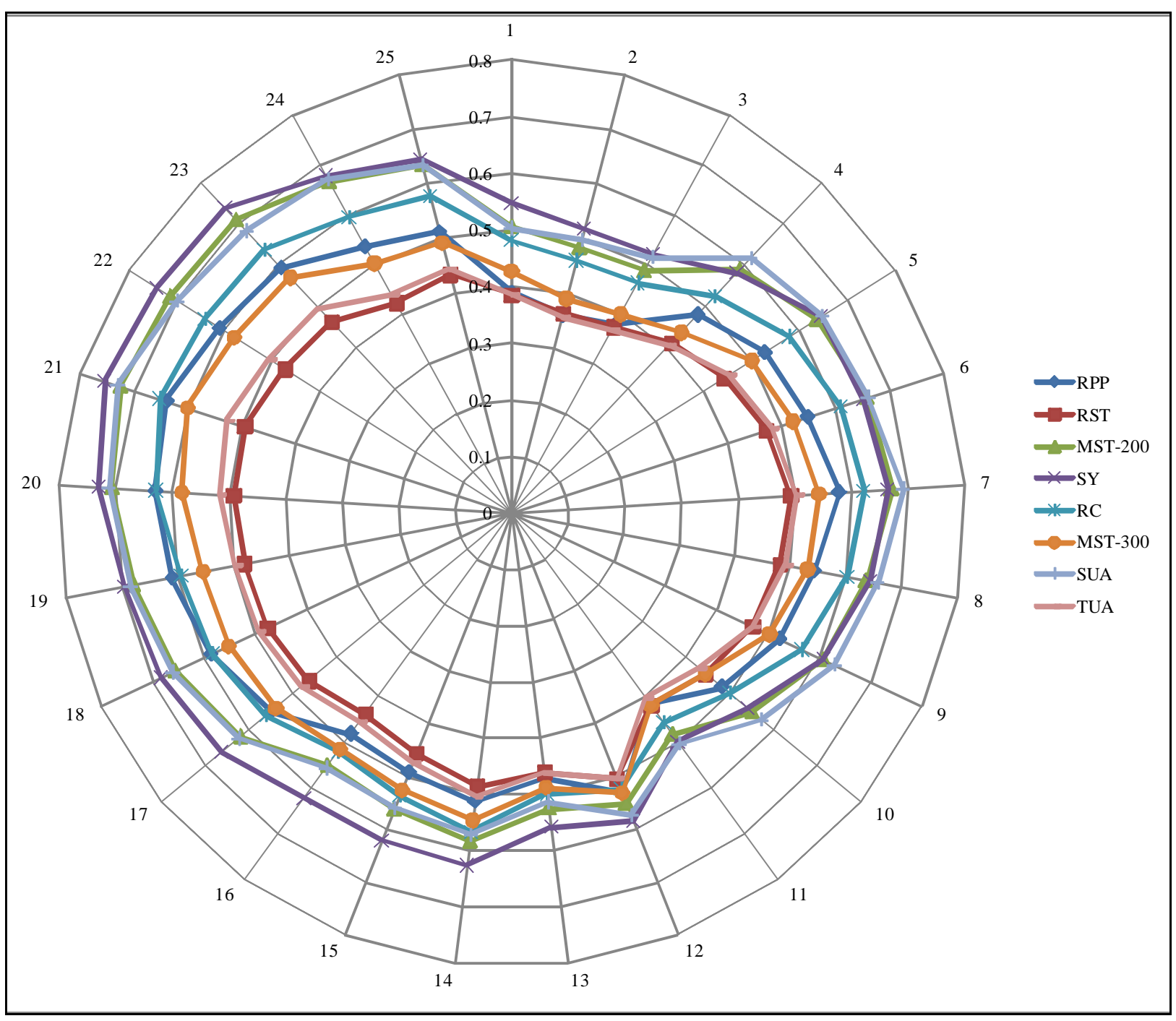

As depicted in Table 8 and Fig. 3, asset SY has top rank among all assets in 17 experiments out of 25 ones. In the rest of the experiments (experiment numbers 4-11), the asset SUA is located in the top level as the winner. As a result, asset SY is the securest asset.

\section{Compare the Proposed Model with the Conventional RAMCAP}

In this subsection, in order to show the capability and suitability of the risk evaluation model proposed in this paper, a comparison of the model with conventional RAMCAP is presented. For this aim, we fulfill the risk analysis by using the conventional RAMCAP for previous case. Based on RAMCAP, risk is a function of only three components threat, vulnerability, and consequence magnitude. An evaluation scale with five judgments $\{1,2,3,4$, and 5$\}$ was applied, where 1 represents minimum judgment level and 5 means the maximum as depicted in Table 8. The results of evaluator team for assets are presented in Table 9. For the aim of comparison, the output of fuzzy TOPSIS is shown in the last column of Table 9. 
Table 8. Definition of the RAMCAP components

\begin{tabular}{|c|c|c|c|}
\hline \multirow[b]{2}{*}{ Rating } & \multicolumn{3}{|l|}{ Components } \\
\hline & Threat (C1) & Vulnerability (C2) & Consequence (C3) \\
\hline 1 & Very Poor (VP) & Very Poor (VP) & Very Poor (VP) \\
\hline 2 & Poor (P) & Poor (P) & Poor (P) \\
\hline 3 & Fair (F) & Fair (F) & Fair (F) \\
\hline 4 & Good (G) & Good (G) & Good (G) \\
\hline 5 & Very Good (VG) & Very Good (VG) & Very Good (VG) \\
\hline
\end{tabular}

Table 9. RAMCAP matrix

\begin{tabular}{ccccccc}
\hline & C1 & C2 & C3 & $\begin{array}{c}\text { Risk } \\
\text { value }\end{array}$ & & \multicolumn{2}{c}{ Rank based on security } \\
\cline { 5 - 7 } & & & & 48 & 7 & 5 \\
RPP & 4 & 3 & 4 & & RAMCAP result & Fuzzy TOPSIS result \\
RST & 3 & 4 & 3 & 36 & 5 & 7 \\
MST-200 & 3 & 3 & 2 & 18 & 1 & 2 \\
SY & 4 & 1 & 2 & 8 & 4 & 1 \\
RC & 3 & 4 & 2 & 24 & 6 & 4 \\
MST-300 & 5 & 3 & 3 & 45 & 1 & 3 \\
SUA & 1 & 2 & 4 & 8 & 7 & 6 \\
TUA & 4 & 4 & 3 & 48 & & 3 \\
\hline
\end{tabular}

As can be easily seen, the final classification shows significant differences between the results of RAMCAP and fuzzy TOPSIS. According to the output of RAMCAP, the risk value belong to a limited set and never takes into account values such as 7, 11, 13, 14, 17, 19, 21. Furthermore, from a computational point of view, there is a reduction in the capability of the conventional RAMCAP methodology to define a precise and accurate rank, then grouping the critical assets into a few categories and allocating similar rank to different assets. This should be considered that organizations are forced with two main limitations finance and time. The allocation of resources for unnecessary activities leads to waste opportunities. Besides different sets of vulnerability, threat, and consequence may generate an identical value of risk; however, the risk implication may not necessarily be the same. For example, two assets RPP and TUA have values of 4, 3, 4 and 4, 4, 3 for C1, C2 and C3 respectively. Both these assets will have a risk value of 48; however, the risk implications of these two assets may be completely various. Other example is two assets SUA and SY, which have values of 1, 2, 4 and 4, 1, 2 for C1, C2 and C3 respectively, with similar risk value 8; nevertheless, the risk implications of these two assets may be entirely different. Finally, the relative importance among C1, C2 and C3 are not considered. This may not be accurate in real world problems. Therefore, the outputs of proposed model are more accurate. This may result a more precise, accurate and sure risk analysis for protection.

\section{Conclusion}

In response to the rapid growth of military industries and increasing the capability of 
terrorists to carry out destructive work, particularly for the critical infrastructures, the need for assets controls and risk measures has caught much time and attention of governments and responsible sectors. On the other hand, the measurement of risk is difficult for decision makers to be precisely and accurately measured because of the intangible nature of dangerous and threats. Most previous studies only used the RAMCAP parameters to evaluate risk. In this paper, a new framework for evaluating risk in critical infrastructures is introduced and developed. The model proposed extends the conventional RAMCAP through introducing new parameters the effects on risk level to obtain a more precise classification of the existing risks.

According to the complexity of the proposed model due to exist different criteria, which are in conflicting with each other, a multi-criteria decision making method based on the fuzzy logic theory is described to also handle the uncertainty of decision making problem. This technique helps decision maker to specify relative importance of criteria and to determine judgments by means of linguistic variables. A case study is presented in order to demonstrate the potential applications of this methodology. Then a comparison between the proposed model and conventional RAMCAP is fulfilled. The results of the comparison show some shortages of the conventional RAMCAP as listed in the following:

(1) The values of risk evaluation belong to a limited set,

(2) Grouping the assets into a few categories,

(3) Allocating similar rank to different assets,

(4) Neglecting the relative importance of criteria.

\section{References}

American Petroleum Institute (API) and National Petrochemical Refiners Association (NPRA), 2004. Security Vulnerability Assessment Methodology for the Petroleum and Petrochemical Industries (2nd ed.), (Appendix C1). Available at http://www.npra.org/publications/general/SVA_2nd_Edition.pdf.

Ashtiani, B., Haghighirad, F., Makui, A., \& Montazer, G. (2009). Extension of fuzzy TOPSIS method based on interval-valued fuzzy sets. Applied Soft Computing, 9: 457-461. http://dx.doi.org/10.1016/j.asoc.2008.05.005

ASME Innovative Technologies Institute (ASME-ITI), (2006). RAMCAP (Risk Analysis and Management for Critical Asset Protection); the Framework, ASME Innovative Technologies Institute, LLC (Chapter 1). Available at http://www.personal.psu.edu/jsd222/SRA311/RAMCAPframework_Risk_Analysis_and_Man age.pdf

Awasthi, A., Chauhan, S. S., \& Omrani, H. (2011). Application of fuzzy TOPSIS in evaluating sustainable transportation systems. Expert Systems with Applications, 38 (10): 12270-12280. http://dx.doi.org/10.1016/j.eswa.2011.04.005

Aydogan, E. K. (2011). Performance measurement model for Turkish aviation firms using the rough-AHP and TOPSIS methods under fuzzy environment. Expert Systems with 
Applications, 38(4): 3992-3998. http://dx.doi.org/10.1016/j.eswa.2010.09.060

Brashear, J., Olstein, M., Binning, D., \& Stenzler, J. (2007). RAMCAP ${ }^{\mathrm{TM}}$; Risk Analysis and Management for Critical Asset Protection for the Water and Wastewater Sector. Water Environment Federation, pp. 2199-2212.

Brashear, J.P., \& Jones, J.W. (2010). Risk Analysis and Management for Critical Asset Protection. Wiley Handbook of Science and Technology for Homeland Security (edited by john G. Voeller), John Wiley \& Sons, Inc, pp. 93-106.

Chen, T. Y., Tsao, Ch. Y. (2008). The interval-valued fuzzy TOPSIS method and experimental analysis. Fuzzy Sets and Systems, 159: $1410 \quad$ - 1428. http://dx.doi.org/10.1016/j.fss.2007.11.004

Ebrahimnejad, S., Mousavi, S. M., \& Mojtahedi, S. M. H. (2009). A fuzzy decision-making model for risk ranking with an application to an onshore gas refinery. Int. J. Business Continuity and Risk Management, $1(1)$ 38-66. http://dx.doi.org/10.1504/IJBCRM.2009.028950

Grassi, A., Gamberini, R., Mora, C., \& Rimini, B. (2009). A fuzzy multi-attribute model for risk evaluation in workplaces. Safety Science, 47: 707-716. http://dx.doi.org/10.1016/j.ssci.2008.10.002

Gumus, A. T. (2009). Evaluation of hazardous waste transportation firms by using a two step fuzzy-AHP and TOPSIS methodology. Expert Systems with Applications, 36: 4067-4074. http://dx.doi.org/10.1016/j.eswa.2008.03.013

Jolai, F., Yazdian, S. A., Shahanaghi, K., \& Khojasteh, M. A. (2011). Integrating fuzzy TOPSIS and multi-period goal programming for purchasing multiple products from multiple suppliers. Journal of Purchasing \& Supply Management, 17: 42-53. http://dx.doi.org/10.1016/j.pursup.2010.06.004

Kaya, T., \& Kahraman, C. (2011). Multicriteria decision making in energy planning using a modified fuzzy TOPSIS methodology. Expert Systems with Applications, 38: 6577-6585. http://dx.doi.org/10.1016/j.eswa.2010.11.081

Kelemenis, A., Ergazakis, K., \& Askounis, D. (2011). Support managers' selection using an extension of fuzzy TOPSIS. Expert Systems with Applications, 38: 2774-2782. http://dx.doi.org/10.1016/j.eswa.2010.08.068

Krohling, R.A., \& Campanharo, V.C. (2011). Fuzzy TOPSIS for group decision making: A case study for accidents with oil spill in the sea. Expert Systems with Applications, 38: 4190-4197. http://dx.doi.org/10.1016/j.eswa.2010.09.081

Kuo, M. S., Tzeng, G.-H., \& Huang, W. C. (2007). Group decision making based on concepts of ideal and anti-ideal points in fuzzy environment. Mathematical and Computer modeling, 45(3/4), 324-339. http://dx.doi.org/10.1016/j.mcm.2006.05.006

Liao, Ch.N., \& Kao, H.P. (2011). An integrated fuzzy TOPSIS and MCGP approach to supplier selection in supply chain management. Expert Systems with Applications, 38: 10803-10811. http://dx.doi.org/10.1016/j.eswa.2011.02.031

Roghanian, E., Rahimi, J., Ansari, A. (2010). Comparison of first aggregation and last aggregation in fuzzy group TOPSIS. Applied Mathematical Modelling, 34: 3754-3766. 
http://dx.doi.org/10.1016/j.apm.2010.02.039

Sadi-Nezhad, S., \& Damghani, K.Kh. (2010). Application of a fuzzy TOPSIS method base on modified preference ratio and fuzzy distance measurement in assessment of traffic police centers performance. Applied Soft Computing, 10: 1028-1039. http://dx.doi.org/10.1016/j.asoc.2009.08.036

Seçme, N. Y., Bayrakdaroglu, A., \& Kahraman, C. (2009). Fuzzy performance evaluation in Turkish Banking Sector using Analytic Hierarchy Process and TOPSIS. Expert Systems with Applications, 36: 11699-11709. http://dx.doi.org/10.1016/j.eswa.2009.03.013

Singh, R.K., \& Benyoucef, L. (2011). A fuzzy TOPSIS based approach for e-sourcing. Engineering Applications of Artificial Intelligence, 24: 437-448. http://dx.doi.org/10.1016/j.engappai.2010.09.006

Sun, Ch. Ch. (2010). A performance evaluation model by integrating fuzzy AHP and fuzzy TOPSIS methods. Expert Systems with Applications, 37: 7745-7754. http://dx.doi.org/10.1016/j.eswa.2010.04.066

Sun, Ch.Ch., \& Lin, G.T.R. (2009). Using fuzzy TOPSIS method for evaluating the competitive advantages of shopping websites. Expert Systems with Applications, 36: 11764-11771. http://dx.doi.org/10.1016/j.eswa.2009.04.017

Torlak, G., Sevkli, M., Sanal, M., \& Zaim, S. (2011). Analyzing business competition by using fuzzy TOPSIS method: An example of Turkish domestic airline industry. Expert Systems with Applications, 38: 3396-3406. http://dx.doi.org/10.1016/j.eswa.2010.08.125

Yang, T., \& Hung, C. C. (2007). Multiple-attribute decision making methods for plant layout design problem. Robotics and Computer-Integrated Manufacturing, 23(1): 126-137. http://dx.doi.org/10.1016/j.rcim.2005.12.002

Yu, V.F., \& Hu, K.J. (2010). An integrated fuzzy multi-criteria approach for the performance evaluation of multiple manufacturing plants. Computers \& Industrial Engineering, 58: 269-277. http://dx.doi.org/10.1016/j.cie.2009.10.005

Yue, Zh. (2011). An extended TOPSIS for determining weights of decision makers with interval numbers. Knowledge-Based Systems, 24: 146-153. http://dx.doi.org/10.1016/j.knosys.2010.07.014

Cox, L.A.J. (2009). Risk Analysis of Complex and Uncertain Systems. Springer Science+Business Media, LLC, (Chapter 15). http://dx.doi.org/10.1007/978-0-387-89014-2

Zadeh, L. A. (1965). Fuzzy sets. Inform. Contr. 8:338-53. http://dx.doi.org/10.1016/S0019-9958(65)90241-X 